\title{
Congenital heart defects through 30 years*
}

\author{
Alf Meberg \\ Department of Paediatrics, Vestfold Hospital Trust, Tønsberg, Norway \\ Email: alfmeberg@yahoo.no
}

Received 21 April 2012; revised 22 May 2012; accepted 29 May 2012

\section{ABSTRACT}

Aim: To assess basic trends in epidemiology of congenital heart defects (CHDs). Method: Population based prospective observational study. Material: CHDs in infants born alive in a Norwegian county 1982-2011. Results: In 828/71 217 infants (12 per 1000) a CHD was diagnosed. The prevalence increased from 8 to 12 per 1000 after introduction of early echocardiography in newborns with suspected CHD from $1986(p=0.0001)$. Ventricular septal defect (VSD) was the dominating CHD (474; 57\%). In 222 (27\%) the CHDs were missed and diagnosed after discharge from hospital after birth. Twelve critical CHDs (causing death or requiring invasive procedures before 28 days of life) were missed. Prenatal diagnosis of critical CHDs increased from 4/67 (6\%) born 1997-2006 to 4/11 (36\%) born 2007-11 $(p=0.01)$. In $177(21 \%)$ a syndrome or extracardial defect occurred. The occurrence of CHDs associated with chromosomal disorders $(60 / 73(82 \%)$ trisomies) more than doubled from the cohort born in the first 10-year period 1982-91 (0.6 per 1000) to the last 2002-11 (1.4 per 1000) $(\mathrm{p}<0.0001)$ in parallel with increasing births in women $\geq 35$ years old in the population. $237(29 \%)$ underwent therapeutic procedures $(203(86 \%)$ surgery, of whom 16 after initial catheter intervention, and $34(14 \%)$ catheter intervention alone). $39 / 237$ (16\%) died, $101(43 \%)$ were repaired and $97(41 \%)$ had some minor residual defect. The death rate declined significantly from $65 / 532$ (12\%) born 1982-2001 to 11/296 (4\%) born 2002-11 $(p=0.0001) .37 / 76(49 \%)$ deaths occurred within 28 days after birth. Conclusions: The rate of detection of CHDs increased substantially after introduction of echocardiography in newborns with suspected CHD, especially VSDs. Some critical CHDs were overlooked. The prenatal detection rate of such defects increased. The prevalence of CHDs with associated chromosomal disorders increased in parallel with increasing

"The author is a consultant neonatologist at the Vestfold Hospital Trust, supporting the study financially. maternal age in the population. Most deaths occurred during the neonatal period. Increasing survival increases the load on long-term follow-up programmes.

Keywords: Congenital Heart Defects; Prevalence; Associated Malformations; Spontaneous Cure; Surgery; Outcome

\section{INTRODUCTION}

Congenital heart defect (CHD) is the most common type of malformations. The panorama of CHDs ranges from small ventricular septal defects (VSDs) which spontaneously close days or weeks after birth, to complex disorders causing an early death. Progress in diagnostics and in medical and surgical treatment have improved the outcome for CHDs during the last decades [1,2]. Few studies have, however, presented complete data for place and time of diagnosis, associated syndromes and malformations, therapeutic intervention and outcome of children with CHDs in an unselected population over a long period of time. This broad perspective is important to understand the dynamics of CHDs as a group, and for evaluation of the effectiveness of pediatric cardiology programmes. Further it may shed some light on challenges to be faced by adult cardiology from children with persistent cardiac morbidity growing into adult age $(\mathrm{GUCH}-$ programmes) [3]. Such a perspective may be of special interest because new diagnostic technology (echocardiography) and strategies (prenatal heart screening, echocardiography in newborn infants with suspected CHD, pulse oximetry screening) have improved the time and rate for detection of CHDs, and thus changed the visible panorama of such defects in the population $[4,5]$.

The aims of the present study were to evaluate main trends for prevalence of CHDs, quality of diagnostic strategies, occurrence of associated syndromes and malformations, spontaneous resolvement, need for therapeutic procedures (surgery, catheter interventions), outcome and need for referral to a GUCH-programme in an unselected population of infants and children born alive during a 30-year period (1982-2011). 


\section{MATERIAL AND METHODS}

\subsection{Population}

Vestfold County Central Hospital has the only delivery unit (about 2300 deliveries a year) and the only paediatric department (including neonatal special and intensive care unit, and paediatric outpatient clinic) caring for children with CHD in the County of Vestfold, Norway (total population 230,000). A close collaboration between the paediatric department and the Child Health Centres in the county (ambulatory pediatric services from our department to the health centres), with the pediatric departments of the hospitals in the neighbouring counties, and the regional paediatric cardiology centre makes it possible to obtain (nearly) complete epidemiological data from the population.

\subsection{Diagnostic Strategies}

All newborn infants were clinically examined by a pediatrician during their stay in the nursery or neonatal unit before discharge from hospital after birth, preferentially on the first or second day after birth. If a CHD was suspected, chest X-ray, blood pressure measurements, pulse oximetery, blood tests or echocardiography were undertaken at the discretion of the pediatrician. During the period 1982-85, however, healthy newborn infants with cardiac murmurs were followed clinically through the first 6 months of life and were not routinely referred for echocardiography if the murmur disappeared. From 1986 newborn infants with clinical signs of CHD were investtigated with echocardiography as soon as possible and before discharge from hospital. Children referred to our outpatient clinic or admitted to our paediatric ward for cardiological investigations were for the whole period referred for echocardiography if clinical examination by a paediatrician and/or standard laboratory tests indicated a possible heart defect.

Ultrasound screening of the fetus, offering one examination at about 18th week of gestation for all pregnant women was established 1986. This has been the basic strategy up to now, however, with increasing focus on detecting fetal malformations, especially during the last decade.

\subsection{Patients}

All CHDs in the 30-year cohort of children belonging to the Vestfold population (mother resident in the county at delivery) born alive 1982-2011 were prospectively registered. 90\% were born at the Vestfold County Central Hospital. Time and place for diagnosis, the rate of spontaneous cure, therapeutic procedures (surgery, catheter interventions) and their results, persistence of non-operated defects, associated syndromes and extracardiac de- fects, and mortality were registered. Patients dying with an unrecognised CHD detected by autopsy were included. Data were not available for pregnancies terminated because of fetal malformations.

The patients were followed until 16 years of age, when transferred to a GUCH-programme. The collection of data was finished April 1, 2012, allowing at least three months of follow-up for the last born infants in the cohort.

\subsection{Classification of CHDs}

Classification of the CHDs was carried out according to international standards [6]. An arbitrary system of categorization of the many combinations of congenital heart defects was used, which allows a single diagnostic categorization per patient [7]. Excluded from the series were: 1) children with bicuspid aortic valve only with no aortic stenosis (AS) or regurgitation; 2) children with cardiac arrythmia only; 3) patent ductus arteriosus (PDA) in all preterm infants, and in term infants unless the duct stayed open after 6 months of age; 4) infants with isolated left to right interatrial shunt not present beyond the age of 6 months.

As critical CHDs were defined those causing death or requiring invasive therapeutic procedures before 28 days of life.

\subsection{Statistics}

Statistical differences between groups were tested by chi-square test and Fischer's exact test. A probability value of $p<0.05$ was regarded as significant.

\section{RESULTS}

\subsection{Prevalence}

A CHD was diagnosed in 828 out of 71,217 live born infants (12 per 1000). The prevalence increased from 8 per 1000 for infants born $1982-85$ to 12 per 1000 in those born 1986-2011 ( $\mathrm{p}<0.0001)$, with no significant changes during the last period. The increase was caused by improved detection of VSDs, from 4.1 to 7 per $1000(\mathrm{p}=$ 0.0001). Table 1 shows the distribution and Figure 1 the prevalences of the CHDs. VSDs accounted for $474 / 828$ (57\%), og which $382(81 \%)$ were located to the muscular part of the interventricular septum and $92(19 \%)$ to the membraneous/perimembranous part.

\subsection{Diagnosis}

Figure 2 shows time and place for diagnosis. In 606/828 (73\%) patients the CHD was detected before discharge from hospital after birth (13 prenatally, 585 by routine examination in the nursery or clinically after transferral to the neonatal intensive care unit (NICU) because of 


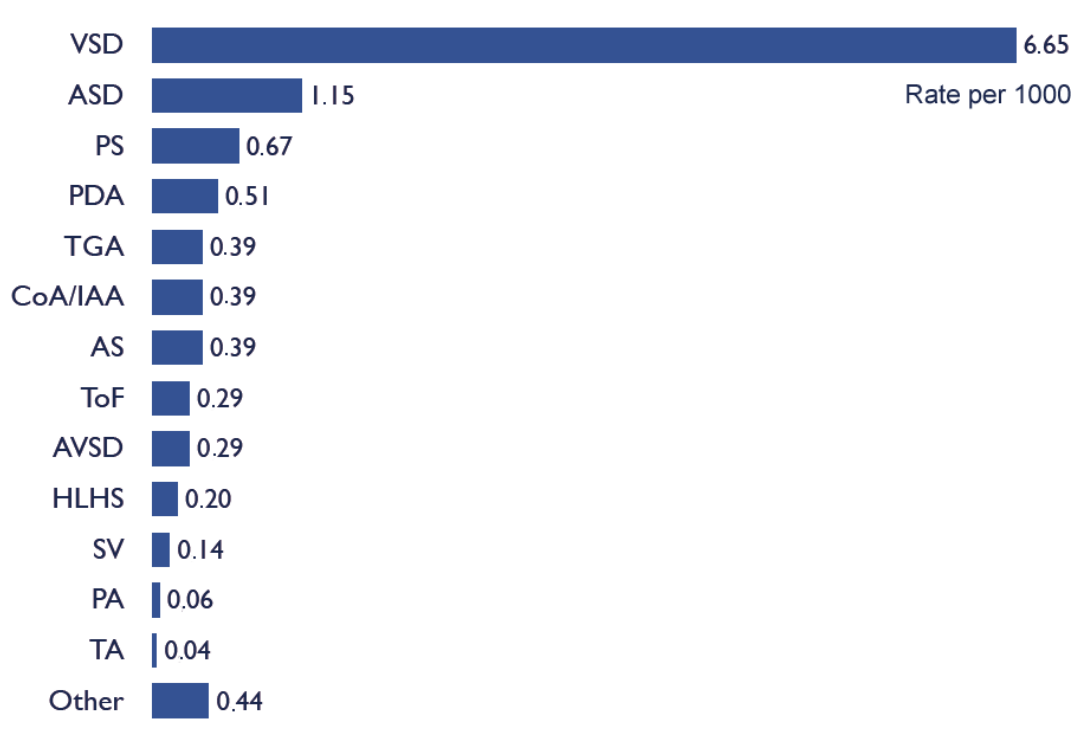

Figure 1. Prevalences of congenital heart defects $(n=828)$.

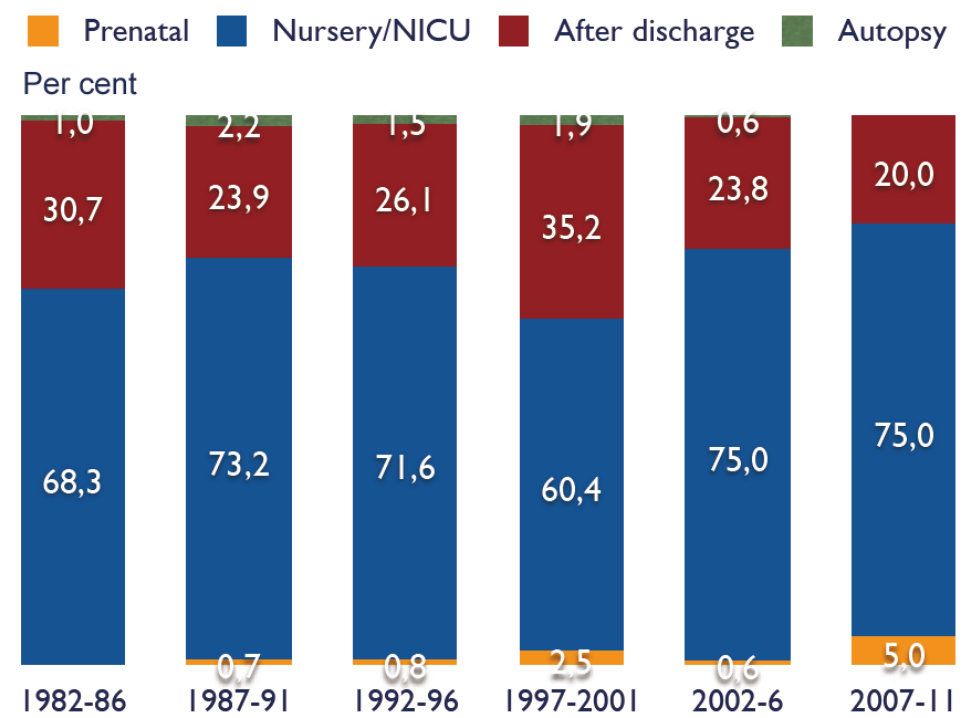

Figure 2. Time and place for diagnosis of congenital heart defects $(\mathrm{n}=$ $828)$; detected prenatally $(n=13)$, clinically in nursery/NICU $(n=585)$ or after discharge from hospital $(n=220)$, and unrecognized defects detected by autopsy $(\mathrm{n}=10)$.

symptoms of disease, and 8 unrecognized defects detected by autopsy). In 222 (27\%) cases the CHDs were missed to be detected after disharge ( 2 unrecognized and detected by autopsy) (Table 2). Twelve (1.5\%) missed cases were critical CHDs (causing death or requiring invasive procedures before 28 days of life). Only 4/67 (6\%) critical CHDs were diagnosed prenatally in infants born 1997-2006, compared to 4/11 (36\%) born 2007-11 $(\mathrm{p}=0.01)$. Of the missed cases $134 / 222(60 \%)$ were diagnosed during the first year of life, and the rest during the following years up to adolescence (Figure 3). VSDs accounted for most of the missed cases $(97 / 222 ; 44 \%)$. Figure 4 shows the percentages of cases detected before or after discharge for the different types of CHDs.

\subsection{Associated Syndromes and Malformations}

In $177(21 \%)$ of the CHD cases extracardial syndromes or malformations occurred. Of these, 73 (41\%) had chromosomal disorders, 30 (17\%) recognizable syndromes (microdeletions allocated to this group) and 74 $(42 \%)$ simple or multiple extracardiac malformations. The occurrence of CHDs with associated chromosomal disorders increased significantly, and in parallel with increasing incidence of births in women $\geq 35$ years of age (Figure 5). 60/73 (82\%) of the chromosomal disorders were trisomies. 


\subsection{Spontaneously Resolved CHDs}

A total of 347 (42\%) CHDs resolved spontaneously, of which 292 (84\%) were VSDs. The spontaneous closure rate for all VSDs was $292 / 474(62 \%)$. Of the VSDs located to the muscular part of the interventricular septum $270 / 382(71 \%)$ resolved compared to $22 / 92$ (24\%) located to the membraneous/perimembranous septum $(\mathrm{p}<$ $0.0001)$. Other resolving defects were atrial septal defect (ASD) $(33 / 82 ; 40 \%)$, pulmonary stenosis (PS) $(15 / 48$; $31 \%)$, PDA $(5 / 36 ; 14 \%)$ and AS $(2 / 28 ; 7 \%)$.

\subsection{Therapeutic Interventions}

In a total of $237(29 \%)$ patients therapeutic interventions were undertaken, of whom $203(86 \%)$ had surgery (16

Table 1. Distribution of congenital heart defects.

\begin{tabular}{lcc}
\hline Type of defect & $\mathrm{n}$ & $\%$ \\
\hline Ventricular septal defect & 474 & 57.2 \\
-Muscular & 382 & 46.1 \\
-Membranous/perimembranous & 92 & 11.0 \\
Atrial septal defect & 82 & 9.9 \\
Pulmonary stenosis & 48 & 5.8 \\
Patent ductus arteriosus & 36 & 4.3 \\
Transposition of the great arteries & 28 & 3.4 \\
Coarctation of the aorta & 28 & 3.4 \\
Aortic stenosis & 28 & 3.4 \\
Tetralogy of Fallot & 21 & 2.5 \\
Atrioventricular septal defect & 21 & 2.5 \\
Hypoplastic left heart syndrome & 14 & 1.7 \\
Single ventricle & 10 & 1.2 \\
Pulmonary atresia & 41 & 0.5 \\
Truncus arteriosus & 328 \\
Other & 4.7 \\
Total & 31 & 0.4 \\
\hline
\end{tabular}

after initial catheter intervention) and $34(14 \%)$ catheter intervention alone. 39/237 (16\%) died, 101 (43\%) were repaired and $97(41 \%)$ had minor residual defects or palliative procedures as an end-stage operation. Significantly more VSDs located to the membraneous/perimembraneous part than the muscular part of the septum were operated (39/92 (42\%) and 7/382 (2\%) respectively) $(\mathrm{p}<0.0001)$. Of 373 children with CHD born 1982-96, $56(15 \%)$ has a persistent CHD without undergoing therapeutic intervention before passing 16 years of age.

\subsection{Deaths}

Figure 6 shows the mortality rates for the six 5-year cohorts. A total of $76(9 \%)$ patients died. The death rate fell from $65 / 532(12 \%)$ in patients born $1982-2001$ to $11 / 296$ (4\%) born 2002-11 ( $\mathrm{p}=0.0001) .37 / 76(49 \%)$ died within 28 days after birth, of whom only $13(35 \%)$ were operated. Out of 10 deaths where the CHD was unrecognized (diagnosed by autopsy) 7 died during the first day of life from other complex malformations/syndromes, most born prematurely (Table 2).

\subsection{Grown up Children with CHD}

Figure 7 shows the outcome in children with CHD born $1982-96$ at 16 years after birth $(n=373)$. If patients with untreated persistent CHD and those passing surgery without being repaired are to be referred for a GUCH programme, $27 \%$ of all CHD patients would be referred (3.2 per 1000). If those with untreated persistent defects and all patients passing surgery (whether repaired or not) should be referred, these would account for $42 \%$ of all CHD patients (4.9 per 1000).

\section{DISCUSSION}

\subsection{Prevalence}

In this prospective population based study the prevalence of structural CHDs was found as high as 12 per 1000 live

Table 2. Deaths of unrecognized congenital heart defects (CHD) detected by autopsy.

\begin{tabular}{|c|c|c|c|}
\hline Patient & CHD & Associated conditions & Age at death \\
\hline 1 & Ventricular septal defect & Trisomy 18 , immaturity & 30 minutes \\
\hline 2 & Atrioventricular septal defect & Diaphragmatic hernia, prematurity & 30 minutes \\
\hline 3 & Transposition of the great arteries & Potter syndrome, prematurity & 45 minutes \\
\hline 4 & Ventricular septal defect & Trisomy $13 / 15$, prematurity & 50 minutes \\
\hline 5 & Ventricular septal defect & Esophageal atresia, prematurity & 6 hours \\
\hline 6 & Tetralogy of Fallot & Diaphragmatic hernia, prematurity & 6 hours \\
\hline 7 & Double outlet right ventricle & Ivemark syndrome & 9 hours \\
\hline 8 & Ventricular septal defect & Prune belly syndrome & 16 days \\
\hline 9 & Atrial septal defect & Degenerative central nervous system disease & 22 months \\
\hline 10 & Atrial septal defect & Wolf-Hirschorn syndrome & 22 months \\
\hline
\end{tabular}




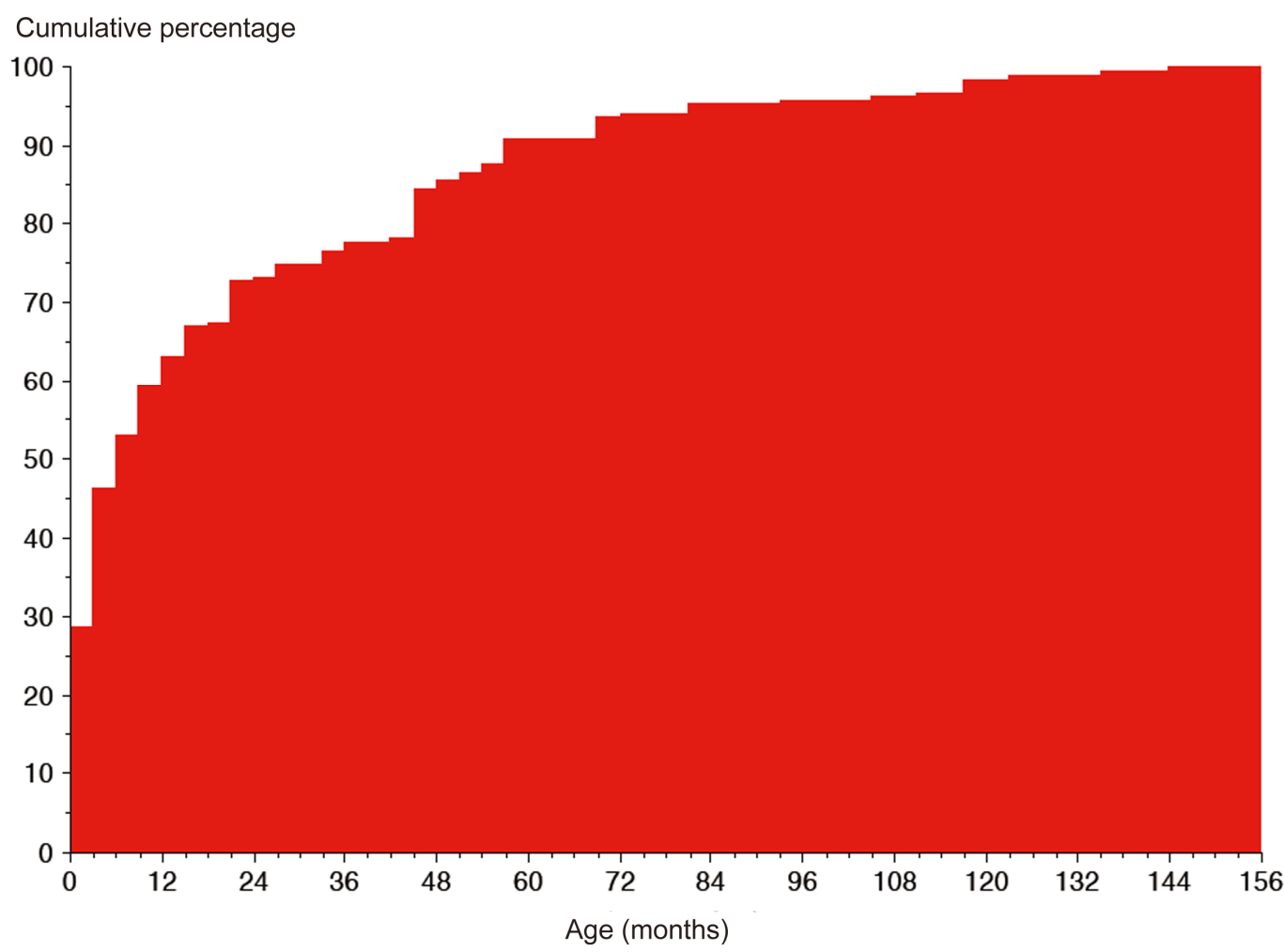

Figure 3. Cumulative percentage of late detected congenital heart defects (after discharge from hospital after birth; $\mathrm{n}=222$ ).

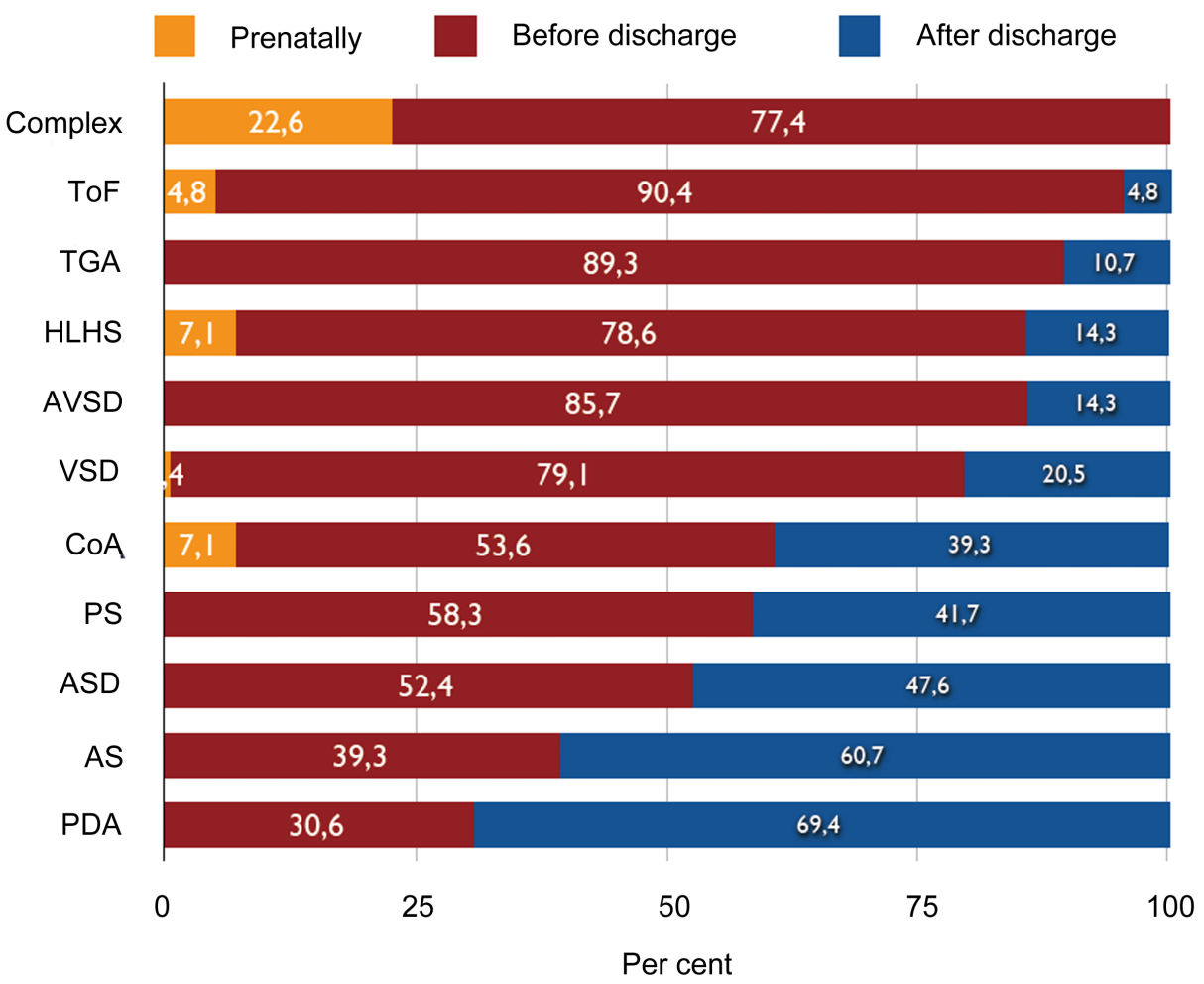

Figure 4. Percentages of different types of congenital heart defects diagnosed prenatally $(\mathrm{n}=$ $13)$, in nursery or NICU before discharge $(\mathrm{n}=593$; including 8 unrecognized CHDs detected by autopsy) or after discharge from hospital after birth $(n=222$; including 2 unrecognized CHDs detected by autopsy). 


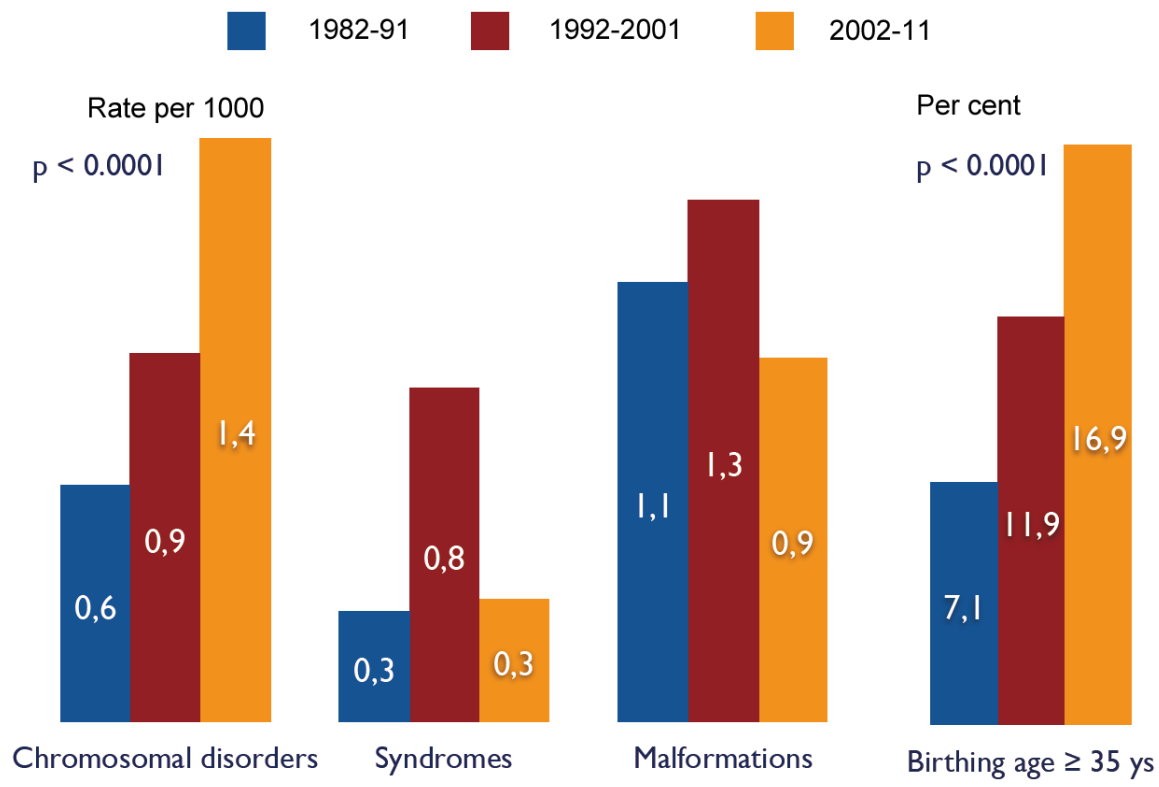

Figure 5. Prevalences of congenital heart defects with associated chromosomal disorders (n $=73)$, recognizable syndromes $(n=30)$ or extracardiac malformations $(n=74)$, and the percentage of births given by women $\geq 35$ years old.

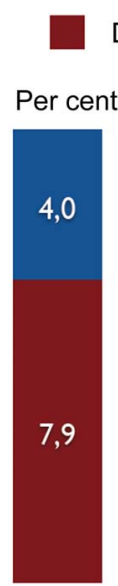

Dead $<28$ days

1982-86

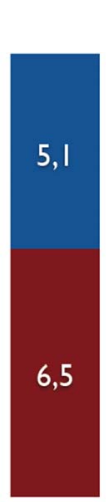

|987-9|

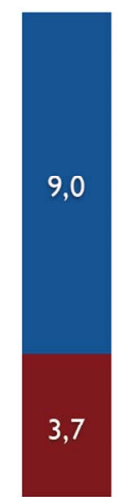

$1992-96$

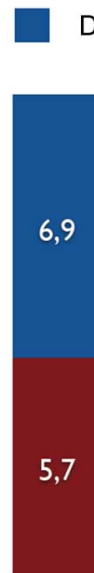

Dead $\geq 28$ days

Figure 6. Neonatal $(<28$ days; $\mathrm{n}=37)$ and postneonatal $(\geq 28$ days; $n=39$ ) deaths in 828 patients with congenital heart defects.

born infants. This is $50 \%$ higher than the 8 per 1000 usually given in the literature $[8,9]$. The high prevalence was caused by an increased detection rate of VSDs, mostly located to the muscular interventricular septum, and with a high spontaneous closure rate. The strategy introduced 1986 with early echocardiography in newborn infants with suspected CHD is the most probable explanation [4] (see below), and not a real increase of VSDs in the population [5]. The other types of CHDs were found to have an unchanged prevalence.

As many as $27 \%$ of the CHDs were diagnosed after discharge from hospital after birth, most of these $(60 \%)$ were diagnosed during the first year of life because of

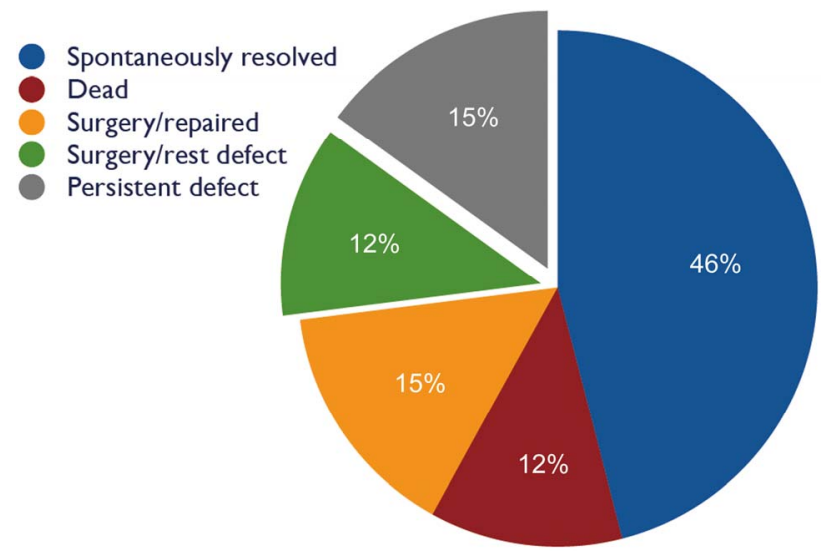

Figure 7. Outcome of congenital heart defects in 373 patients at 16 years after birth.

heart murmur. Thereafter there was a declining influx of new cases up to adolescence. As unrecognized CHDs also are detected in adulthood, the cumulative life time prevalence of CHDs will be even higher than 12 per 1000.

\subsection{Diagnosis}

Most CHDs were detected in the routine clinical examination of newborns in the nursery before discharge home, emphasizing the importance of this clinical screening. A substantial number were, however, missed and detected later on. Some of these were critical heart defects, with the patients readmitted in a circulatory collapse or severe heart failure in need of emergency surgical intervention. It is a main goal to avoid missing such cases, which to a 
large extent are ductus dependent CHDs deteriorating when the ductus arteriosus closes a few days after birth [10]. Fetal heart screening would be the best way of detecting such CHDs, giving possibility for referral for birth at a tertiary care center with high quality cardiologic diagnostics and surgery available. In our study few CHDs in the total population of heart defects were detected prenatally ( $5 \%$ during the last 5 -year period). For critical CHDs the prenatal detection rate was considerably higher (36\% during the last 5 -year period). Fetal heart screening has improved over time, and the detection rate of critical defects may be further improved, as shown in studies from centers of excellence [11]. Universal neonatal pulse oximetry screening may facilitate early postnatal detection of critical CHDs [12,13], before heart failure develops.

For non-critical heart defects VSDs accounted for nearly half of the cases missed. Of the different types of heart defects PDA, AS and ASD were the most overlooked. CHDs may be missed because audible murmurs are not present the first days after birth, and first be detectable when postnatal pulmonary vascular resistance decreases with a contemporary increase of the left-toright shunting through a septal defect or PDA. Valves may gradually grow more stenotic, especially the aortic valves [14].

\subsection{Associated Syndromes/Malformations}

More than one fifth of the CHD cases had associated syndromes or extracardiac malformations. This is in accordance with other studies $[15,16]$. Progress in genetic science has disclosed new etiologies for CHD, e.g. microdeletion syndromes [17]. Detection of a CHD should be followed by a thorough clinical and laboratory examination for associated malformations and genetic disorders.

An intriguing finding was a substantial increase (more than double) in CHDs associated with chromosomal disorders. Most of them were trisomies. In the present study the prevalence of CHDs associated with chromosomal disorders increased in parallel with the percentage of women giving birth $\geq 35$ years of age. It is well known that women with a high age when conceiving are at increased risk of having a fetus with trisomy, most often trisomy 21 [18]. Although increasing ascertainment because of better genetic testing could have influenced the results, this may have more relevance for subtle genetic defects (such as microdeletions) than for major chromosomal disorders (such as trisomies and translocations).

\subsection{Spontaneous Resolvement}

Nearly half of all CHDs (42\%) resolved spontaneously. The vast majority of these were small VSDs located to the muscular part of the interventricular septum. Most of these close during the first year of life $[4,19]$. The closure rate was significantly higher in VSDs located to the muscular part of the interventricular septum compared to VSDs located to the membraneus/perimembranous part ( $71 \%$ vs. $24 \%$ ). The muscular and membraneous septum are embryologically different structures. These two types of VSDs apparently also are two different types of malformations when it comes to the clinical picture, with muscular VSDs occurring four times as frequent, having a three times higher spontaneous closure rate and a nearly negligible need for surgical intervention. Similar conclusions has been drawn by Garne [20], who in muscular and perimembranous VSDs found a spontaneous closure rate of $65 \%$ and $20 \%$ respectively.

Hiraishi et al. [19] screened full-term newborn infants with echocardiography and color Doppler imaging for muscular VSDs. They found the incidence of such defects to be as high as $2 \%$. Spontaneous closure of $76 \%$ of the defects occurred during the first year of life, consistent with our data. The developmental pattern of the muscular ventricular septum includes multiple intervenetricular channels, which are gradually obliterated during intrauterine life by coalescence of the trabecular sheets [21]. From this perspective, closure of small muscular VSDs during the first months after birth may be regarded as a protracted normal developmental process. It may be questioned if such a "defect" should be classified as a structural CHD.

Also ASD, PDA and valvar stenosis (especially PS) had a significant spontaneous resolvement.

\subsection{Therapeutic Interventions}

Nearly one third of all CHD cases were in need of some therapeutic procedure, most surgery, however, also catheter interventions. Catheter intervention has gained increasing popularity for closing ASD, PDA and even VSDs, as well as balloon aortic and pulmonary valvulotomy and dilatation or stenting for coarctation of the aorta (CoA). Intervention carry risks for rest or residual defects, which occurred in nearly half of all cases passing therapeutic procedures. Most were, however, minor ones. If a therapeutic procedure is truly corrective (or curative) the individual should achieve a normal functional status and anticipated life expectancy, and experience no further cardiac morbidity related to the heart defect. In a large study Morris and Menashe [2] found that individuals with surgery for ASD, PS and PDA closest to satisfy these criteria, and the surgical repair to be considered corrective and essentially curative. For other defects such as tetralogy of Fallot (ToF), VSD, coarctation of the aorta $(\mathrm{COA}), \mathrm{AS}$ and transposition of the great arteries (TGA) continuous cardiac mortality through 25 years after surgery prevented use of this re- 
strictive definition of correction. Even repaired CHDs may have an increased death risk over time, some caused by letal arrythmias [22]. Probably all patients undergoing therapeutic interventions should be included in a lifelong follow-up programme.

\subsection{Deaths}

Mortality declined significantly over time, reflecting a steady improvement in cardiologic diagnostics and therapeutic interventions. Nearly half of the deaths occurred during the first four weeks of life. A substantial number of these cases died without therapeutic procedures being undertaken because of the complexity of the CHDs or severe associated syndromes or extracardiac malformations. Further deaths occurred during infancy after the neonatal period, causing a total of $80 \%$ of the deaths to occur during the first year of life.

Some cases died with an unrecognized CHD detected by autopsy. However, most of these cases died very early (minutes or hours after birth) from associated extracardiac malformations, most of them born prematurely. None of these deaths were judged to be avoidable. A positive trend for minimizing deaths of patients with unrecognized CHDs is found in other studies [23].

\subsection{GUCH Programmes}

The improved prognosis for CHDs has increased the number of patients in need for long-term follow-up. Special GUCH-programmes have been established to take care of these patients. Such programmes focus on their heart condition as well as growth and development, education and work, family planning and pregnancy [24]. It may be disputed what heart conditions need such specialized follow-up. If all patients with a CHD are defined as risk cases, even those with spontaneous resolvement, $1 \%$ of the general population of children will need a GUCH-programme. If only risk groups are referred (such as untreated patients with a persistent CHD and selected groups passing surgery) $0.3 \%-0.5 \%$ of the general population of children will need a life-long specialized care.

\section{CONCLUSION}

The prevalence of CHDs increased significantly after introduction of echocardiography in newborns with suspected CHD, all caused by an increased detection rate of small muscular VSDs. The prevalence of CHDs with associated chromosomal disorders increased in parallel with increasing high birthing age. A substantial number are overlooked in the routine heart screening after birth, even some critical CHDs. The prenatal detection rate of critical CHDs increased. Most deaths occurred during infancy, especially in the neonatal period. Increasing survival increases the need for referral for long-term fol- low-up.

\section{ACKNOWLEDGEMENTS}

The study was supported by a grant from Vestfold Hospital Trust.

\section{REFERENCES}

[1] Rice, M.J., McDonald, R.W., Reller, M.D. and Sahn, D.J. (1996) Pediatric echocardiography: Current role and a review of technical advances. The Journal of Pediatrics, 128, 1-14. doi:10.1016/S0022-3476(96)70421-3

[2] Morris, C.D. and Menashe, V.D. (1991) 25-year mortality after surgical repair of congenital heart defect in childhood: A population-based cohort study. JAMA: The Journal of the American Mediacal Association, 266, 3447 3452. doi:10.1001/jama.1991.03470240069035

[3] Somerville, J. (1990) "Grown-up" survivors of congenital heart disease: Who knows? Who cares? British Journal of Hospital Medicine, 43, 132-136.

[4] Meberg, A., Otterstad, J.E., Frøland, G., Sørland, S. and Nitter-Hauge, S. (1994) Increasing incidence of ventricular septal defects caused by improved detection rate. Acta Paediatrica, 83, 653-657. doi:10.1111/j.1651-2227.1994.tb13102.x

[5] Dickinson, D.F. (1998) Ventricular septal defect: (Not) another epidemic? Cardiology in the Young, 8, 423-424. doi:10.1017/S1047951100007046

[6] International Society of Cardiology (1970) Classification of heart disease in childhood. VBR Offsetdrukkerij, Groningen.

[7] Fyler, D.C., Buckley, L.P., Hellenbrand, W.E., Cohn, H.E., Kirklin, J.W., Nadas, A.S., et al. (1980) Report of the New England Regional Infant Cardiac Program. Pediatrics, 65, 377-461.

[8] Archer, N. (2005) Cardiovascular disease. In: Rennie, J.M. Ed., Roberton's Textbook of Neonatology, 4th Edition, Elsevier Churchill Livingstone, Philadelphia, 619-660.

[9] Bernstein, D. (2011) Epidemiology and genetic basis of congenital heart disease. In: Kliegman, R.M., Stanton, B.F., Schor, N.F., St. Geme, J.W. III and Behrman, R.E., Eds., Nelson Textbook of Pediatrics, 19th Edition, Elsevier Saunders, Philadelphia, 1549. doi:10.1016/B978-1-4377-0755-7.00418-8

[10] Mellander, M. and Sunnegårdh, J. (2006) Failure to diagnose critical heart malformations in newborns before discharge-An increasing problem? Acta Pcediatrica, 95, 407-413. doi:10.1080/08035250500541910

[11] Tegnander, E., Eik-Nes, S.H., Johansen, O.J. and Linker, D.T. (1995) Prenatal detection of heart defects at the routine fetal examination at 18 weeks in a non-selected population. Ultrasound in Obstetrics \& Gynecology, 5, 372-380. doi:10.1046/j.1469-0705.1995.05060372.x

[12] Meberg, A., Brügmann-Pieper, S., Due, R. Jr., Eskedal, L., Fagerli, I., Farstad, T., et al. (2008) First day of life pulse oximetry screening to detect congenital heart defects. The Journal of Pediatrics, 152, 761-765. doi:10.1016/j.jpeds.2007.12.043 
[13] Meberg, A., Andreassen, A., Brunvand, L., Markestad, T., Moster, D., Nietsch, L., et al. (2009) Pulse oximetry screening as a complemetatry strategy to detect critical congenital heart defects. Acta Paediatrica, 98, 682-686. doi:10.1111/j.1651-2227.2008.01199.x

[14] Kiráhly, P., Kapusta, L., Van Lier, H., Hofman A.O. and Daniëls O. (1997) Natural history of congenital aortic valvar stenosis: An echo and Doppler cardiographic study. Cardiology in the Young, 7, 188-193.

[15] Grech, V. and Gatt, M. (1999) Syndromes and malformations associated with congenital heart disease in a population-based study. International Journal of Cardiology, 68, 151-156. doi:10.1016/S0167-5273(98)00354-4

[16] Eskedal, L., Hagemo, P., Eskild, A., Aamodt, G., Seiler, K.S. and Thaulow, E. (2004) A population-based study of extra-cardiac anomalies in children with congenital cardiac malformations. Cardiology in the Young, 14, 600-507. doi:10.1017/S1047951104006043

[17] Fokstuen, S., Arbenz, U., Artan, S., Dudly, F., Bauersfeld, U., Brecevic, L., et al. (1998) 22q11.2 deletions in a series of patients with non-selective congenital hert defects: Incidence, type of defects and parental origin. Clinical Genetics, 53, 63-69. doi:10.1034/j.1399-0004.1998.531530113.x

[18] Lyons Jones K. (2006) Genetics, genetic counceling, and prevention. In: Jones, K.L., Ed., Smith's Recognizable Patterns of Human Malformation, 6th Edition, Elsevier Saunders, Philadelphia, 796-816.

\section{Abbreviations}

AS: Aortic stenosis;

ASD: Atrial septal defect;

AVSD: Atrioventricular septal defect;

CoA: Coarctation of the aorta;

GUCH: Grown up children with heart disease;

HLHS: Hypoplastic left heart syndrome;

IAA: Interrupted aortic arch;
[19] Hiraishi, S., Agata, Y., Nowatari, M., Oguchi, K., Misawa, H, Hirota, H., et al. (1992) Incidence and natural course of trabecular ventricular septal defect: Two-dimensional echocardiography and color Doppler flow imaging study. The Journal of Pediatrics, 120, 409-415. doi:10.1016/S0022-3476(05)80906-0

[20] Garne, E. (2006) Atrial and ventricular septal defectsEpidemiology and spontaneous closure. The Journal of Maternal-Fetal Neonatal Medicine, 19, 271-276. doi:10.1080/14767050500433817

[21] Ben-Shachar, G., Arcilla, R.A., Lucas, R.V. and Manasek, F.J. (1985) Ventricular trabeculations in the chick embryo heart and their contribution to ventricular and muscular septal development. Circulation Research, 57, 759-766. doi:10.1161/01.RES.57.5.759

[22] Liberthson, R.R. (1996) Sudden death from cardiac causes in children and young adults. The New English Journal of Medicine, 334, 1039-1044. doi:10.1056/NEJM199604183341607

[23] Wren, C., Reinhardt, Z. and Khawaja, K. (2008) Twentyyear trends in diagnosis of life-threatening neonatal cardiovascular malformations. Archives of Disease in Childhood (Fetal and Neonatal Edition), 93, F33-F35. doi:10.1136/adc.2007.119032

[24] Perloff, J.K. (1991) Congenital heart disease in adults. A new cardiovascular subspeciality. Circulation, 84, 18811890. doi:10.1161/01.CIR.84.5.1881

NICU: Neonatal intensive care unit;

PS: Pulmonary stenosis;

PDA: Patent ductus arteriosus;

SV: Single ventricle;

TGA: Transposition of the great arteries;

ToF: Tetralogy of Fallot;

VSD: Ventricular septal defect. 